\title{
Parameter Order Selection of Autoregressive Model for Classification of Ground Surveillance Radar Targets
}

\author{
Dimitrije Bujaković ${ }^{1)}$ \\ Milenko Andrić ${ }^{1)}$ \\ Davorin Mikluc ${ }^{1)}$ \\ Boban Bondžulić $^{1)}$
}

\begin{abstract}
In this research the order selection of autoregressive model parameters for classification of signals from the ground surveillance radar audio-output is considered. For this purpose, a measure based on maximal separability between used radar classes (clutter, person walking, person running, group of persons walking, group of persons running, vehicle) is suggested. Determined order of the autoregressive model is compared to the information criterion proposed by Akaike for different used windows. After the feature reduction of used real radar Doppler echo signals, it is showed that the proposed measure determines as optimal significantly lower order with a higher separability between used classes of radar targets
\end{abstract}

Key words: ground surveillance radar, radar signals, signals classification, autoregressive model.

\section{Introduction}

$\mathrm{O}$ NE of the main tasks of using sensors in military application is their application in the battlefield situational awareness. It is a continuous process of collecting and processing information gathered using different sensors in order to estimate possible threats during some time period, [1]. For the purpose of this process, sensors that work in different part of electromagnetic spectrum (radar, television cameras, thermal cameras, seismic sensors, etc.) or the information fusion from different sensors can be used. The usage of each type of sensors have some advantages and some limitations. The advantage of the optoelectronic sensors over the radar is that their usage provides passive detection, high resolution and high resistance on the electronic countermeasures usage. On the other hand, comparing to the cameras, the radar can work in complex meteorological conditions and provides higher distance for target detection.

Using radar systems often is limited on their role in air surveillance. In this case, there are relatively high contrasts between the radar target and background and the fact that air targets cannot stop their moving so easily. In contrast to this, the ground surveillance radar deals with the additional problems. On the ground it needs to detect targets with a small velocity that move in a strong clutter environment, [2]. Also, it needs to detect targets that could occasionally appear and disappear because of their moving on rough terrain. Beside all these challenges, ground surveillance radars are often used not only for the detection and classification of targets that move on the ground, but also for the targets that fly at small heights (helicopters, drones, etc.).

The key tasks of the ground surveillance radar are detection and classification of the targets. In typical radar systems, the detection problem is fully automatized, while the classification is still done based on the operator's experience. Radar emits signal of a certain frequency and due to moving target the received signal frequency is different than the emitted one. The frequency change is linearly dependent on the target velocity and this change in frequency is called the Doppler frequency. If the target parts have some additional moving beside the bulk moving, it will cause additional frequency modulation that is called micro-Doppler signature of radar targets. The received signal after demodulation is often in audio band and it can be heard via headphones. The operator listens to a sound from the ground surveillance radar audio-output and decides about the presence and type of radar targets based on a unique target micro-Doppler signature, [3].

Signals from the audio-output of the ground surveillance radars are often time non-stationary, and the time-frequency analysis is often used, [4]. One of the most used is spectrogram, but some new time-frequency distributions are proposed, such as S-method [5], multiwindow S-method [6], modified B-distributions [7], etc. In [8-13], the features extracted from the spectrogram are used for the classification of various human movement or various radar targets. Authors, in [8], have proposed using six features extracted from the spectrogram to classify different human movements of one person (walking, running, walking while holding a stick, crawling, boxing while moving forward, boxing while standing in place, sitting still). In [9], a fuzzy system for classification of vehicles and persons who have moved in the ground surveillance radar line-of-sight is projected. Inputs in this system were central Doppler frequency and bandwidth around it. The projections of spectrogram on the time and frequency axis are used as the features vector for radar signal

\footnotetext{
1) University of Defence, Military Academy, Generala Pavla Jurišića Šturma 33, 11000 Belgrade, SERBIA

Correspondence to: Dimitrije Bujaković; e-mail:dimitrije.bujakovic@gmail.com
} 
classification in [10]. Authors, in [11], used bandwidth of the spectrogram projection on the frequency axis as a feature vector for classification of a person, group of persons and vehicles using the Support Vector Machine (SVM). In [12], using the multiwindow S-method to extract features in order to determine persons who carry some objects in one or both hands is proposed. The problem of classifying people and animals is presented in [13], where the periodicity of human walking was used to determine the key feature for a proper classification.

Authors, in [14], used the greedy Gaussian mixture (GMM) in order to classify different radar targets (vehicle, person walking and running, group of persons walking and running). As a feature, the cepstrum coefficients and autoregressive parameters of signal from radar audio-output were used. In [15] different features (linear predictive coding, cepstrum and mel-cepstrum coefficients) used in speech recognition problems are used. As an input in neural network for classification of the ground surveillance radar signals, in [16], the autoregressive parameters (AR) of signal from radar audio-output are used. In [14-16], the order selection of autoregressive parameters is not considered, while in [17] it is pointed that the major issue in the implementation of these parameters is the proper order selection. As measures for the autoregressive parameters order selection in [17], the measures based on the prediction error power (Final Prediction Error - FPE and Akaike Information Criterion AIC) are proposed. In [18], a new measure for the AR parameters order selection based on the Kullback's symmetric divergence for a large-sample model is proposed, while in [19] a measure for a small-sample model is proposed. Using the principle of minimal length description, in [20] a new method for the estimation of autoregressive parameters order is proposed. In [21] a new method for covariance matrix estimation of autoregressive parameters vectors is proposed. Based on this estimated matrix, a new modification of the Akaike Information Criterion for vectors of autoregressive process is proposed.

Common for all the previously mentioned methods for classification is that it is not considered the optimal order selection of autoregressive parameters for their usage for the classification. In this research a new measure for the order selection of autoregressive parameters is proposed in order to perform classification. This measure is based on the scattered measures. Conducted results on the real radar echo signals show that using new proposed measure achieves lower order selection, with better separation between the analyzed classes.

The rest of the paper is organized as follows: in Section 2 a database of the real radar signals that were used for analysis is described. Section 3 briefly introduces the autoregressive parameter estimation using a modified covariance method. In Section 4 the Akaike Information Criterion and measure proposed in this research are defined. Some results of using defined measure for the feature extraction of the ground surveillance radar signals are discussed in Section 5. Some conclusions and further research are given in Conclusion.

\section{Database of radar signals}

For the purpose of this research, in order to collect real signals from the output of ground surveillance radar, a coherent pulse - Doppler radar was used. This radar is used for detection of the ground moving targets on small distances from the radar. The radar emits signal whose carrier frequency is $f_{t}=16.8 \mathrm{GHz}$ (Ku-band), while the average power of emitted signal is $P_{a}=5 \mathrm{~mW}$. Pulse width of the emitted signal is $\tau=14.63 \mu \mathrm{s}$ and pulse repetition frequency is $P R F=34.18 \mathrm{kHz}$. Range resolution of used radar is $\Delta R=150$ $\mathrm{m}$, while elevation resolution and azimuth resolution are $\Delta \varepsilon=7.5^{\circ}$ and $\Delta \varphi=5^{\circ}$, respectively. Monostatic radar configuration is used for collecting real-world data with parabolic antenna (vertical polarization and antenna gain $G=32 \pm 2 \mathrm{~dB}),[22]$.

Ground surveillance radar used in this research has so called audio-output, which can be used for detecting and classifying radar targets by the operator. When emitted radar signal falls on the moving target, it is scattered and radar signals that reflect from different parts of the target have Doppler shifts that are proportional to the radial velocity of the target moving part. Due to the emitted signal frequency, these Doppler signals are in the audio-band. Listening to this signal, it can be noticed that different targets produce a unique sound that could be easily recognized by the operator. The moving targets were automatically detected and tracked using the radar for the recording procedure and by this continuous target echo records are achieved. The range between the radar and targets was from $200 \mathrm{~m}$ to $450 \mathrm{~m}$, while the targets are moving on the asphalt road toward and from the radar in the radar line of sight. The target motion was fully controlled and only a direct motion (toward and away from the radar) was conducted. Each person in the group contributes to the radar returned signal equally due to the frontal marching. In each scenario only one target class is present in the radar line-of-sight.

The amplitude of raw Doppler radar data is in the range of $\pm 1 \mathrm{~V}$. Audio signal from the radar output is driven to the computer sound card microphone input and recorded onto it. Data was saved as digitized WAV files, and the sampling rate was set to the $f_{s}=4 \mathrm{kHz}$. The digitized data can be easily processed using MATLAB ${ }^{\mathrm{TM}}$. We analyzed a portion of radar echo records of $10 \mathrm{~s}$ duration that consist of 40000 samples. During the collection process different radar targets were recorded: person walking, person running, group of persons walking, group of persons running, vehicle and situation where there is no radar target present. Detailed description of the scenarios and collected data from the ground surveillance radar audio-output can be found in [23].

\section{Parameters estimation of the autoregressive signal model using modified covariance method}

Parameters estimation of the autoregressive signal model can be done in various methods, such as autocorrelation method, covariance method, modified covariance method, etc. In [17] these methods are explained in detail, while in this research the modified covariance method for parameters estimation of the autoregressive signal model of the ground surveillance radar echo signals is described.

"Forward" optimal predictor of signal $x[n]$ is defined as, [17]:

$$
\hat{x}[n]=-\sum_{p=1}^{k} a[p] x[n-p]
$$

while "backward" optimal predictor of signal $x[n]$ is defined as, [17]:

$$
\hat{x}[n]=-\sum_{p=1}^{k} a^{*}[p] x[n+p]
$$


where $a[p]$ and $a^{*}[p]$ are the autoregressive parameters and conjugate complex autoregressive parameters, respectively, and $k$ is the parameter order of the autoregressive process. In both cases the power of minimal prediction error is equal to white noise variance, $\sigma^{2}$. Modified covariance method estimates the autoregressive process parameters using minimal average power prediction error "forward" and "backward", [17]:

$$
\hat{\rho}=\frac{1}{2}\left(\hat{\rho}^{f}+\hat{\rho}^{b}\right)
$$

where

$$
\hat{\rho}^{f}=\frac{1}{N-k} \sum_{n=k}^{N-1}\left|x[n]+\sum_{p=1}^{k} a[p] x[n-p]\right|^{2}
$$

and

$$
\hat{\rho}^{b}=\frac{1}{N-p} \sum_{n=0}^{N-1-p}\left|x[n]+\sum_{k=1}^{p} a^{*}[k] x[n+k]\right|^{2}
$$

In order to minimize the prediction error power (3), it is needed to differentiate this power in order to parameters $a[p]$, for $p=1,2, \ldots, k$. This problem can be resolved as solving complex gradient, [17], and

$$
\begin{aligned}
& \frac{\partial \hat{\rho}}{\partial a[l]}=\frac{1}{N-k}\left(\sum_{n=k}^{N-1}\left(x[n]+\sum_{p=1}^{k} a[p] x[n-p]\right) x^{*}[n-l]+\right. \\
& \left.+\sum_{n=0}^{N-1-k}\left(x^{*}[n]+\sum_{p=1}^{k} a^{*}[p] x[n+p]\right) x[n+l]\right)=0
\end{aligned}
$$

for $l=1,2, \ldots, k$. After rearranging, (6) can be expressed as:

$$
\begin{aligned}
& \sum_{p=1}^{k} \hat{a}[p]\left(\sum_{n=k}^{N-1} x[n-p] x^{*}[n-l]+\sum_{n=0}^{N-1-k} x^{*}[n+p] x[n+l]\right)= \\
& -\left(\sum_{n=k}^{N-1} x[n] x^{*}[n-l]+\sum_{n=0}^{N-1-k} x^{*}[n] x[n+l]\right)
\end{aligned}
$$

for $l=1,2, \ldots, k$. If ( 7$)$ is expressed in the matrix form, it concludes to, [17]:

$$
\left[\begin{array}{cccc}
c_{x x}[1,1] & c_{x x}[1,2] & \ldots & c_{x x}[1, k] \\
c_{x x}[2,1] & c_{x x}[2,2] & \ldots & c_{x x}[2, k] \\
\vdots & \vdots & \ddots & \vdots \\
c_{x x}[k, 1] & c_{x x}[k, 1] & \ldots & c_{x x}[k, k]
\end{array}\right]\left[\begin{array}{c}
\hat{a}[1] \\
\hat{a}[2] \\
\vdots \\
\hat{a}[k]
\end{array}\right]=-\left[\begin{array}{c}
c_{x x}[1,0] \\
c_{x x}[2,0] \\
\vdots \\
c_{x x}[k, 0]
\end{array}\right]
$$

where

$$
\begin{aligned}
& c_{x x}[j, k]=\frac{1}{2(N-k)} \\
& \cdot\left(\sum_{n=k}^{N-1} x^{*}[n-j] x[n-p]+\sum_{n=0}^{N-1-k} x[n+j] x^{*}[n+p]\right)
\end{aligned}
$$

Solving matrix equation (8) the autoregressive parameters of radar echo signals were determined that could be further used for the classification of the radar targets.

\section{Order selection of the autoregressive parameters}

Order selection of the autoregressive parameters is crucial for using this model in processing of various signals, [17]. If a small process order was chosen, it might lead to the filtration of the analyzed signal spectrum estimation. On the other hand, too large order causes model statistical instability.

In [17] various measures for the selection of optimal autoregressive parameters order are proposed. All of these measures are based on the prediction error power. This power decreases or remains the same as the model order $k$ increases. For this reason it could not simply consider the prediction error power. One of these measures is the final prediction error $(F P E)$ which is defined as:

$$
\operatorname{FPE}(k)=\frac{N+k}{N-k} \hat{\rho}_{k}
$$

where $N$ is data length, $k$ is parameter order and $\rho_{k}$ is prediction error power. For larger $k$ the prediction error power decreases, while expression $(N+k) /(N-k)$ slightly increases. Optimal parameter order $k$ is the one that minimizes $F P E(k)$.

Another measure that is considered in [17] is the Akaike Information Criterion $(A I C)$. This criterion is defined as:

$$
A I C(k)=N \ln \hat{\rho}_{k}+2 k
$$

where $N$ is data length and $\rho_{k}$ is prediction error power. Optimal selection of the parameter order is achieved for a minimal value of $A I C$. This criterion represents the estimation of the Kullback-Leibler distance between the estimated probability density function and real probability density function and this criterion could be applied in various number of problems, not only in optimal parameter order selection.

Selection of the optimal order parameter can be achieved on the previously defined goal - classification. For that purpose we propose a new criterion based on the scattered measure, [24]. Every discussed class is described using a vector of data mathematical expectation $\mathbf{M}_{i}$ and covariance matrix $\boldsymbol{\Sigma}_{i}$. Based on this, within class scatter matrix could be defined as:

$$
\mathbf{S}_{W}=\sum_{i=1}^{L} P_{i} \boldsymbol{\Sigma}_{i}
$$

and between class scatter matrix is defined as:

$$
\mathbf{S}_{B}=\sum_{i=1}^{L} P_{i}\left(\mathbf{M}_{i}-\mathbf{M}_{0}\right)\left(\mathbf{M}_{i}-\mathbf{M}_{0}\right)^{T}
$$

where $L$ is a number of all classes, $P_{i}$ is a priori class probability and $\mathbf{M}_{0}$ is a vector of joint mathematical expectation for all classes together defined as:

$$
\mathbf{M}_{0}=\sum_{i=1}^{L} P_{i} \mathbf{M}_{i}
$$

In [24] different criteria for selection of transformation matrix for the feature reduction are proposed. In this paper the criterion that provides maximal distance between classes and minimal distance within class is used:

$$
J_{1}=\operatorname{tr}\left(\mathbf{S}_{W}^{-1} \mathbf{S}_{B}\right)
$$

Maximum of these criteria provide maximum separation between chosen classes. For a higher parameter order $k$, the value of $J_{1}$ is higher. Higher values of the criterion (15) could provide a higher variance of spectral estimation because of a greater number of parameters that should be calculated. In order to avoid this problem, (15) is modified as:

$$
J_{1 \bmod }(k)=\frac{N-k}{N+k} \operatorname{tr}\left(\mathbf{S}_{W}^{-1} \mathbf{S}_{B}\right)
$$


Besides, $\operatorname{tr}\left(\mathbf{S}_{\mathrm{W}}{ }^{-1} \mathbf{S}_{\mathrm{B}}\right)$ increases with a higher autoregressive parameters order, the expression $(N-k) /(N+k)$ slightly decreases. Optimal order selection is achieved for $k$ that maximizes (16).

In the rest of the paper the autoregressive parameter optimal order selection of the ground surveillance radar signals using $A I C$ is analyzed, (11) as well as the measure proposed in this research (16).

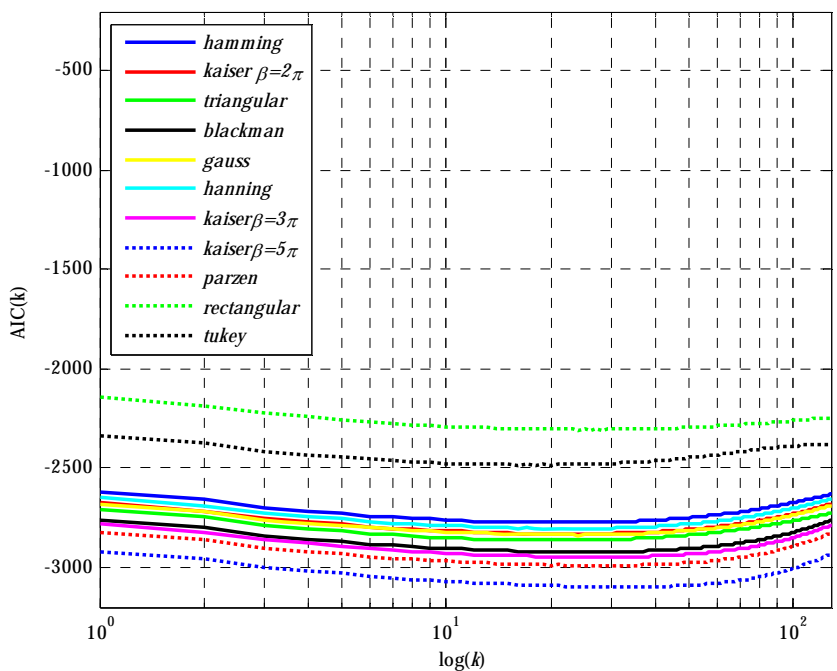

a)

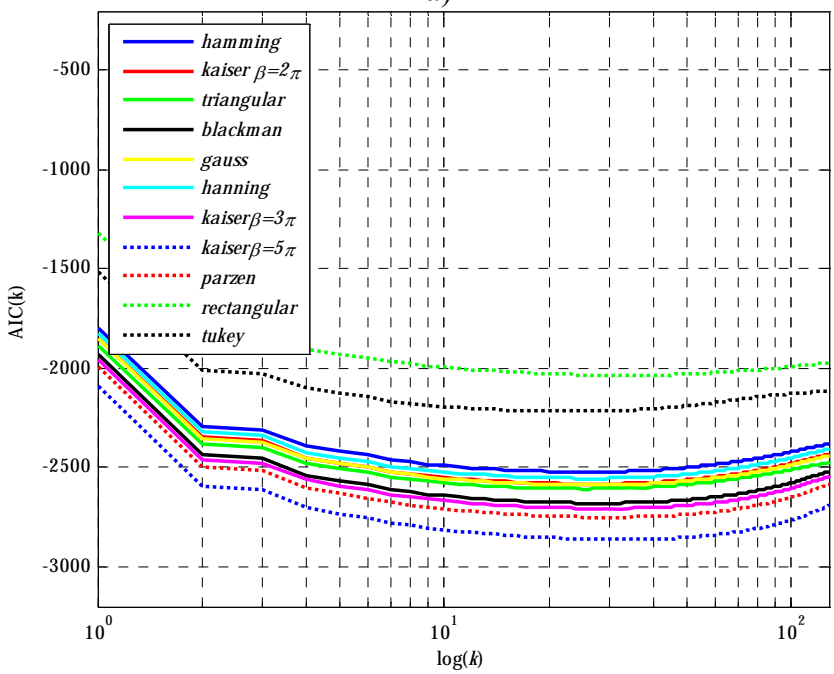

c)

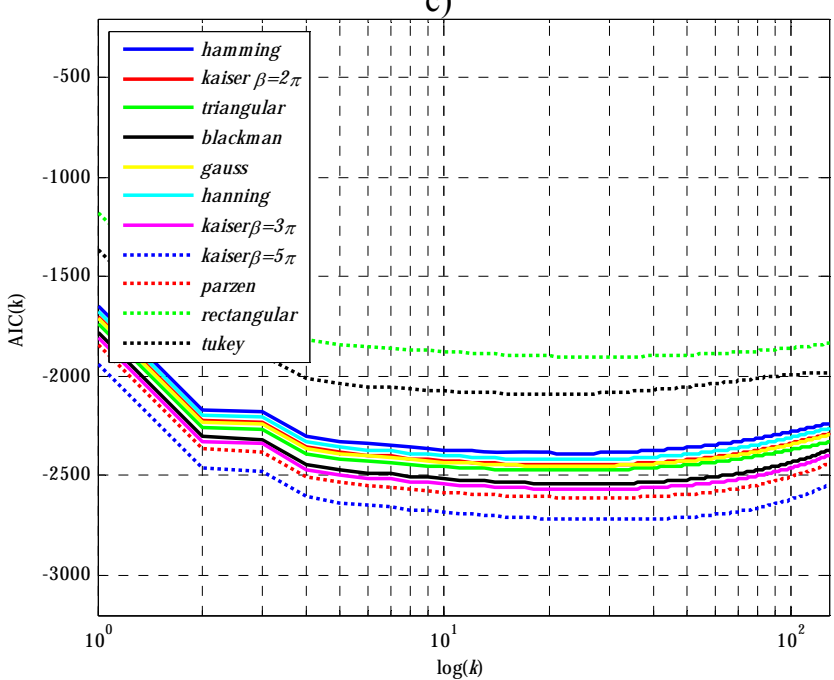

e)

\section{Results}

In this research the autoregressive parameters of radar audio - output signals based on (11) and (16) for different classes of radar echo signals (clutter, person walking, person running, group of person walking, group of person running and vehicles) are compared. It used different windows forms: rectangular, triangular, Blackman, Gauss with the standard deviation of $\sigma=0.4$, Hamming, Hanning, Parzen, Tukey with

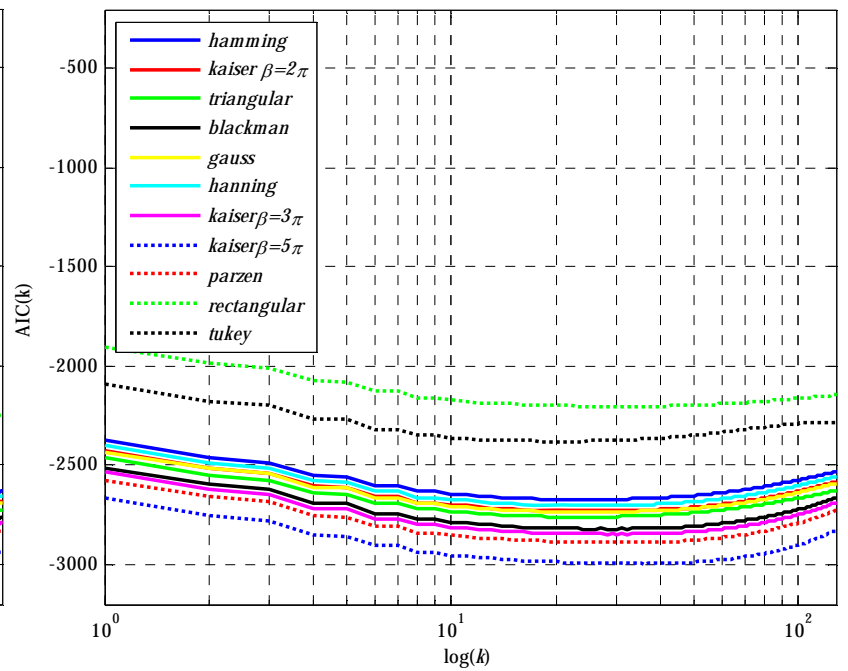

b)

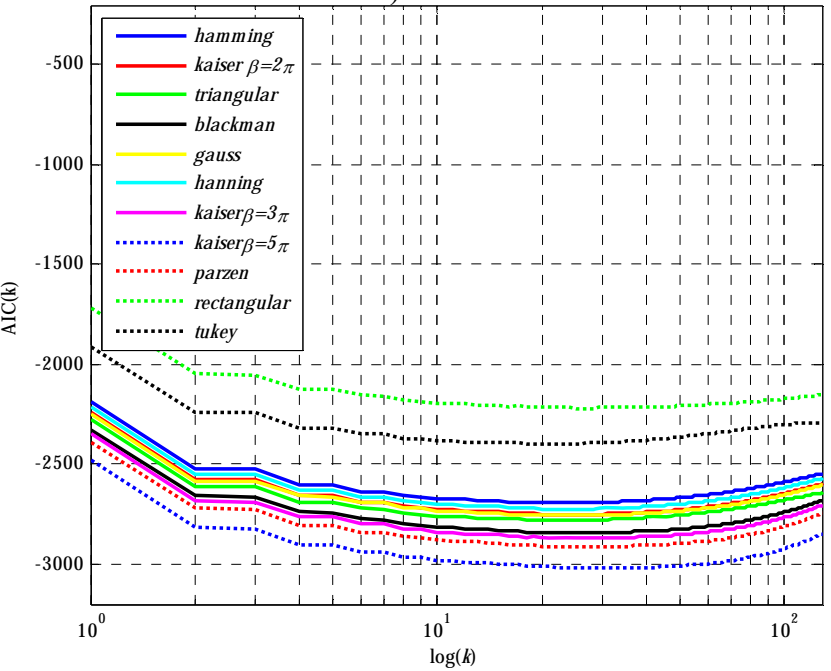

d)

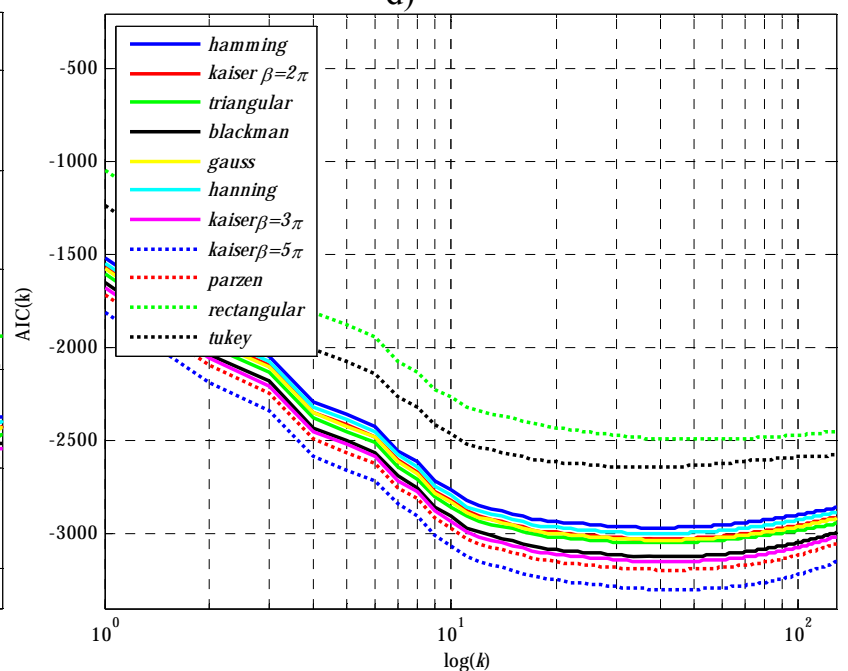

f)

Figure 1. Akaike Information Criterion $(A I C(k))$ calculated in order to average power prediction error as a function of autoregressive parameters order of real radar echo signals that originates from: (a) clutter, (b) person walking, (c) person running, (d) group of persons walking, (e) group of persons running, (f) vehicle 
the form factor $R=0.5$, Kaiser with different form factors $(\beta=2 \pi, \beta=3 \pi, \beta=5 \pi)$. All used windows have the length of $N=512$ samples, and the overlap beside neighbouring windows is $50 \%$. Autoregressive parameter order is between 1 and $N / 4$.

From every of six class there are randomly chosen 500 autoregressive parameters and for each of these parameters $A I C$ is calculated using (11). The average of the AIC values is given in Fig.1.

From Fig.1(a) it is obvious that minimal $A I C(k)$ for real radar signal originated from clutter is achieved for Kaiser window with form factor $\beta=5 \pi$ and $k=34$, where the prediction power error is $\rho_{k}=3.13 \mathrm{dBm}$. Using all others analyzed windows it was selected the same value of autoregressive parameter model for this class of signals, with slightly greater analyzed criterion values. Analysis of $A I C(k)$ calculated for real radar signal that originates from walking person (Fig.1(b)), it is obvious that Kaiser window with form factor $\beta=5 \pi$ is optimal selection, where optimal parameter order is $k=36$ and $\rho_{k}=3.09 \mathrm{dBm}$. Similarly as it was conducted in the cases of signal that originates from clutter, in this case for other types of analyzed windows it was determined model order $k=36$, but with slightly higher criterion values. Fig.1(c) shows $A I C(k)$ calculated for real radar signal from running person. Analysis of this criterion it could be noticed that minimal value of analyzed criterion is achieved for Kaiser window with form factor $\beta=5 \pi$, while optimum order is $k=30$ and power prediction error is $\rho_{k}=5.74 \mathrm{dBm}$. As it was case in previous cases, using other analyzed windows causes higher criterion values with the same optimal parameter order $k=30$. Analysis of Akaike Information Criterion calculated for radar signal from group walking (Fig.1(d)) it could be noticed that minimal value of this criterion is achieved for Kaiser window with form factor $\beta=5 \pi$. Optimum order for this signal class is $k=30$ for any used windows, while power prediction error for Kaiser window is $\rho_{k}=4.04 \mathrm{dBm}$. $A I C(k)$ for group of person running is shown in Fig.1(e). Analysis of this criterion it is noticed that minimal value is achieved for $k=30$ for all analyzed windows, while for Kaiser window with form factor $\beta=5 \pi$ has smallest value and $\rho_{k}=6.59 \mathrm{dBm}$. Values of $A I C(k)$ for real radar signal that originates from vehicle is given in Fig.1(f). Optimal autoregressive parameter order is achieved for $k=46$ for any used window, while for Kaiser window with form factor $\beta=5 \pi$ value of analyzed criterion is minimal and power prediction error is $\rho_{k}=0.38 \mathrm{dBm}$.

Based on the previous analysis, it could be concluded that the values of autoregressive parameter model optimal selection are same in regard to the one class. These values reach minimum for the Kaiser window with form factor $\beta=5 \pi$ regarding to the other analyzed windows. Additionally to this conclusion, it can be noticed that the optimal order selection is dependent from the class of analyzed signal. The Akaike Information Criterion values comparison for all classes of analyzed signals, the parameter order $k=32$ was chosen.

In Fig. 2 the values of proposed criterion $J_{1 \bmod }(k)$ for all analyzed sequences and all analyzed windows are shown.

It could be noticed from Fig.2 that the maximum of the proposed measure $J_{1 \text { mod }}(k)$ is achieved for $k=5$ regardless to the type of analyzed window, while the maximum is for rectangular window. On the other hand, local maximum for $k=29$ could be noticed, while the optimal window is still rectangular.

It can be concluded that a type of used window and optimal order of autoregressive parameters of real radar echo signals is different regarding the used measure. In the rest of the paper the autoregressive model parameters calculated using the Kaiser window with form factor $\beta=5 \pi$ (proposed using $A I C(k))$ and for $k=32$ and using rectangular window for $k=5$ (proposed using $J_{1 \text { mod }}(k)$ ) are analyzed.

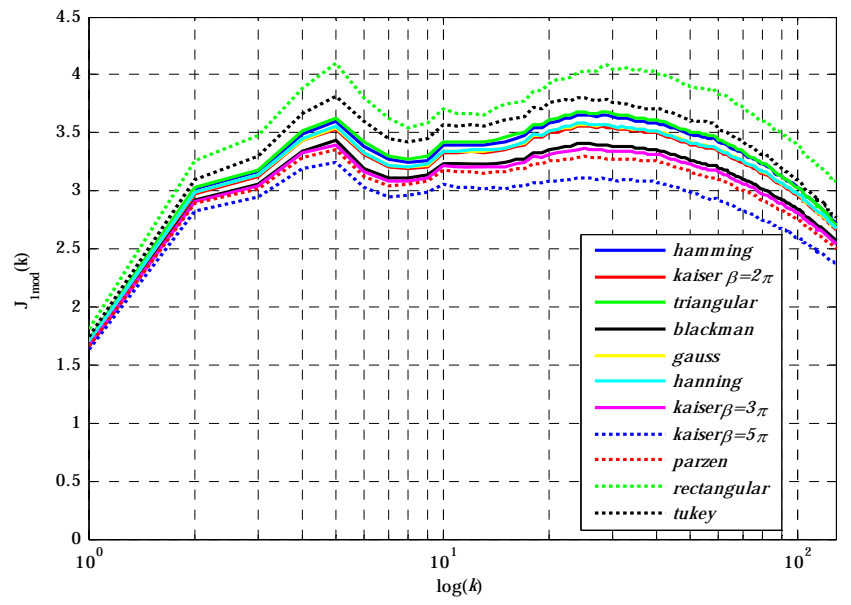

Figure 2. Dependence of measure $J_{1 \text { mod }}(k)$ from order of autoregressive process model of real radar echo signals for analyzed windows

In order to visually present the results of using different measures, the reduction of autoregressive parameters on two dimensions was conducted, [24]. Fig. 3 shows autoregressive parameter model of analyzed real radar echo signals after the reduction on two dimensions.
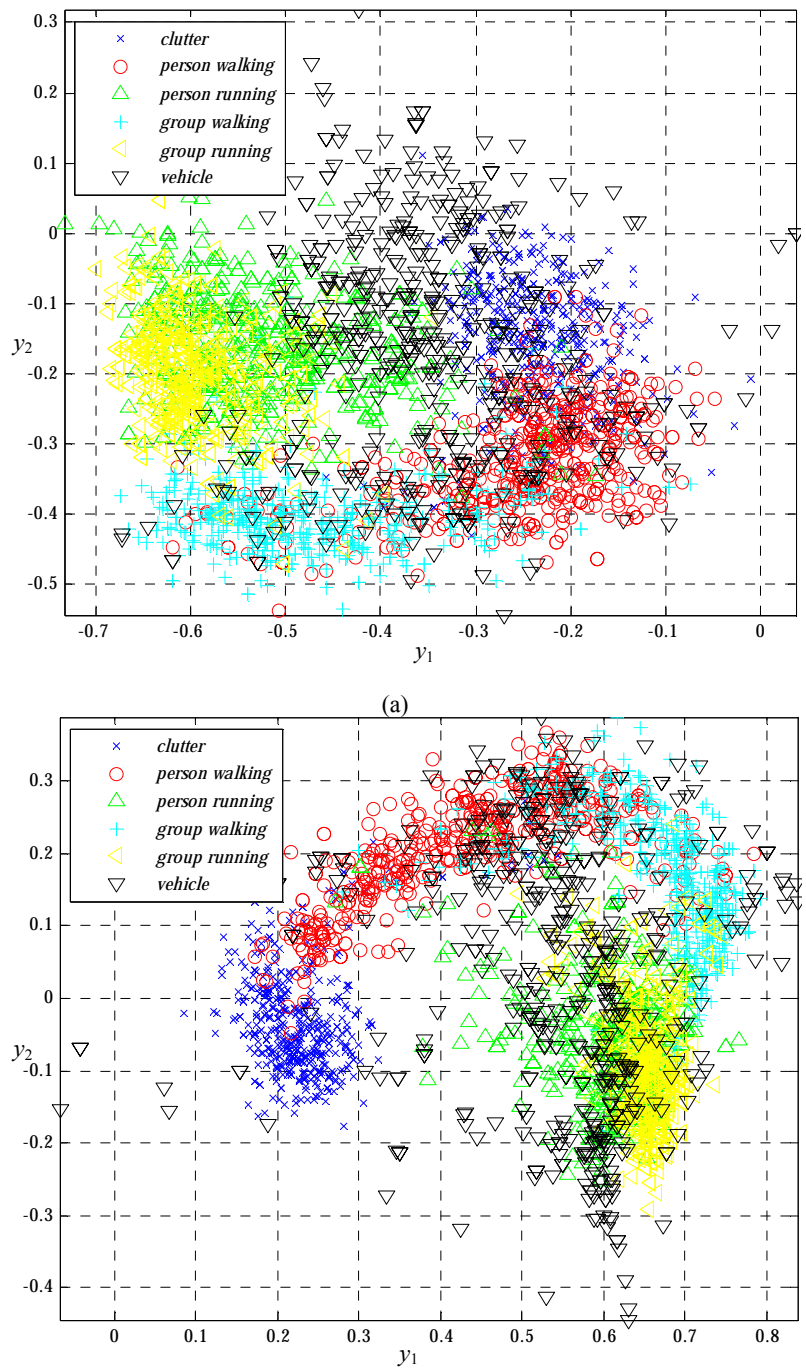

(b)

Figure 3. Autoregressive parameter model of real radar echo signals reduced on two dimenzion for: (a) Kaiser window with form factor $\beta=5 \pi$ and model order $k=32$, (b) rectangular window and model order $k=5$ 
Reduction of autoregressive parameters for the selected Kaiser window with form factor $\beta=5 \pi$ and model order $k=32$ is shown in Fig.3(a). For these parameters it could be noticed that the AR parameters that originate from the vehicle are all over the feature plane. Beside this, parameters from the clutter are grouped and partially overlapped with parameters that correspond the walking person. Class person walking and group of persons walking are near with a lot of overlapping. This overlapping effect between near classes is especially significant for autoregressive parameters that origin from the running person and group of persons running. Analyzing the autoregressive parameter calculated using rectangular window and for model order $k=5$, slightly better separation between analyzed classes of radar signals could be noticed. Beside this, autoregressive parameters for signals that originate from the running person and a group of running persons are very near, while slightly better separation between features that originate from the walking person and a group of person walking could be noticed. However, autoregressive parameters that originate from the vehicle are all over the feature plane and overlapped with all other parameters that origin from other analyzed classes.

\section{Conclusion}

Autoregressive parameters of real ground surveillance radar echo signals are chosen as a feature for classification of these signals. One of the key issues for these parameters implementation is a proper order selection of these parameters. In this research a new measure for autoregressive parameter order selection based on maximal distance between different classes of radar targets is proposed. Results of the order selection are compared with the Akaike Information Criterion. Conducted results show that this criterion is dependent on the class of analyzed signal, while the usage of the Kaiser window with form factor $\beta=5 \pi$ provides minimal value of the Akaike Information Criterion. Meanwhile, using proposed measure in this research, one value for autoregressive parameter order is determined while as the optimal a rectangular window is chosen. Comparing to AIC, the measure proposed in this research is determined as the optimal significantly lower order of the autoregressive parameters. Beside this, proposed measure could not be applied for only one signal class and is dependent on the total number of classes. This measure is not only applied to the problem of the ground surveillance radar signal classification and it can be used for classification of other audio signals. In further research, focus will be on the application of this measure for signals from other sources, as well as for using the autoregressive parameters for classification of signals from the audio-output of ground surveillance radar.

\section{References}

[1] ENDSLEY,M.R., GARLAND,D.J.: Situational Awareness Analysis and Measurement, Lawrence Erlbaum Associates, New Jersey, USA, 2000.

[2] SIMIĆ,S., ZEJAK,A.: The Pulsed-Doppler Radar Audio Signal Detection in the Time-Frequency Domain, 2nd Scientific Conference on Defensive Technologies - OTEH 2007, 03-05. October, 2007, Military Technical Institute, Belgrade SERBIA, ISBN 978-86-8112349-2, 2007, pp. IV45 - IV50.

[3] CHEN,V., LING,H.: The Micro - Doppler Effect in Radar, Artech House, Boston, USA, 2011.

[4] CHEN,V., LING,H.: Time - Frequency for Radar Imaging and Signal Analysis, Artech House, Boston, USA, 2002.
[5] THAYAPARAN,T., STANKOVIĆ,LJ., ĐUROVIĆ,I. : Micro-Doppler Based target Detection and Feature extraction in Indoor and Outdoor Environments, Journal of the Franklin Institute, 2008, 345, (6), pp.700722 .

[6] OROVIĆ,I., STANKOVIĆ,S., THAYAPARAN,T., STANKOVIĆ,Lj.: Multiwindow S-method for Instantaneous Frequency Estimation and its Application in Radar Signal Analysis, IET Signal Processing, 2010, 4 , (4), pp.363-370.

[7] HUSSAIN,Z.M., BOASHASH,B.: Adaptive instantaneous frequency estimation of multicomponent FM signals, Proc. of IEEE Internat. Conf. on Acoustics, Speech and Signal Processing (ICASSP 2000), Istanbul, ISBN 1053-587X, 05-09 June, 2000, pp.657-660.

[8] KIM,Y., LING,H.: Human Activity Classification Based on MicroDoppler Signatures Using a Support Vector Machine, IEEE Trans. Geoscience and Remote Sensing, 2009, 47, (5), pp.1328-1337.

[9] ANDRIĆ,M., ĐUROVIĆ,Ž., ZRNIĆ,B.: Ground Surveillance Radar Target Classification based on Fuzzy Logic Approach, Proc. of the IEEE International Conference on Computer as a Tool (EUROCON 2005), ISBN 1-4244-0049-X, 05-09. September, 2005, Belgrade, SERBIA, pp.1390-1392.

[10] MOLCHANOV,P., ASSTOLA,J., EGIAZARIAN,K., TOTSKY, A.: Classification of Ground Moving Radar Targets using Joint TimeFrequency Analysis, Proc. of IEEE Radar Conference, ISBN 978-14673-0656-0, 07-11. May, 2012, Atlanta, USA, pp.1-6.

[11] ZABALZA,J., CLEMENTE,C., di CATERINA,G., REN,J., SORAGHAN,J., MARSHALL,S.: Robust PCA Micro-Doppler Classification Using SVM on Embedded Systems, IEEE Trans. Aerosp. Electron. Syst., 2014, 50, (3), pp.2304-2310.

[12] OROVIĆ,I., STANKOVIĆ,S., AMIN,M.: A new approach for classification of human gait based on time-frequency feature representations, Signal Processing, 2011, 91, (3), pp.1448-1456.

[13] OTERO,M.: Application of a continuous wave radar for human gait recognition, Proc. of SPIE, ISSN 0277786X, 2005, pp.538-548.

[14] BILIK,I., TABRIKIAN,J., COHEN,A.: GMM-Based Target Classification for Ground Surveillance Doppler Radar, IEEE Trans. Aerosp. Electron. Syst., 2006, 42, (1), pp.267-278.

[15] YESSAD, D., AMROUCHE,A., DEBYECHE,M., DJEDDOU,M.: Micro-Doppler Classification for Ground Surveillance Radar Using Speech Recognition Tools, Proc. of 16th Iberoamerican Congress Progress in Pattern Recognition, Image Analysis, Computer Vision and Applications, ISBN 978-3-642-25084-2, 15-18. November, 2011, Atlanta, USA, pp.1-6.

[16] McCONAGHY,T., LEUNG,H., BOSSE,E., VARADAN,V.: Classification of Audio Radar Signals Using Radial Basis Function Neural Networks, IEEE Trans. Instrumentation and Measurement, 2003, 52, (6), pp.1771-1779.

[17] KAY,S.: Modern Spectral Estimation: Theory\&Application, Prentice Hall, Englewood Cliffs, NJ, USA, 1988.

[18] CAVANAUGH,J.: A large-sample model selection criterion based on Kullback's symmetric divergence, J. Statist. Probabil. Lett, 1999, 42, (4), pp.333-343.

[19] SEGHOUANE,A., BEKARA,M.: A small sample model selection criterion based on Kullback's symmetric divergence, IEEE Trans. Signal Process., 2004, 52, (12), pp.3314-3323.

[20] SCHMIDT,D., MAKALIC,E.: Estimating the Order of an Autoregressive Model Using Normalized Maximum Likelihood, IEEE Trans. Signal Process, 2011, 59, (2), pp.479-487.

[21] KARIMI,M.: Order selection criteria for vector autoregressive models, Signal Processing, 2011, 91, (3), pp.955-969.

[22] ANDRIĆ,M., BUJAKOVIĆ,D., BONDŽULIĆ,B., SIMIĆ,S., ZRNIĆ,B.: Analysis of Radar Doppler Signatures from Human Data, Radioengeneering, 2014, 18, (1), pp.16-32.

[23] BUJAKOVIĆ, D., SIMIĆ,S., ANDRIĆ,M., BONDŽULIĆ,B., MITROVIĆ,S.: Feature Extraction of Real Radar Echo Signals using Spectrogram (in Serbian), Proc. of 59th ETRAN Conference, ISBN 978-86-80509-71-6, 07-11. June, 2015, Srebrno jezero, SERBIA, pp. AU1-6.

[24] FUKUNAGA,K.: Introduction to Statistical Pattern Recognition, 2nd Edition, Academic Press, San Diego, CA, USA, 1990. 


\title{
Izbor reda parametara autoregresivnih modela za klasifikaciju ciljeva izviđačkih radara
}

\begin{abstract}
U ovom istraživanju razmatran je izbor reda parametara autoregresivnih modela radi klasifikacije signala sa izlaza izviđačkih radara. Za ovu svrhu predložena je mera zasnovana na maksimalnoj separabilnosti razmatranih klasa radarskih ciljeva (nema radarskog signala, osoba hoda, osoba trči, grupa osoba hoda, grupa osoba trči i vozilo). Dobijeni red parametara autoregresivnih modela poređen je sa redom određenim primenom informacionog kriterijuma koji je predložio Akaike za različite oblike prozora. Nakon redukcije dimenzija dobijenih vektora obeležja izdvojenih korišćenjem realnih radarskih signala, pokazano je da predložena mera predlaže značajno manji red autoregresivnih procesa uz povećanu separabilnost razmatranih klasa radarskih ciljeva.
\end{abstract}

Ključne reči: izviđački radar, radarski signali, klasifikacija signala, autoregresivni model.

\section{Выбор порядка параметров авторегрессивных моделей, чтобы классифицировать цели разведывательных радиолокационных станций}

\begin{abstract}
В данном исследовании рассматривается выбор порядка параметров авторегрессивных моделей для классификации выходных сигналов разведывательных радиолокационных станций. Для этой цели были предложены меры, основанные на максимальной отделимости рассматриваемых класс радиолокационных целей (нет радиолокационного сигнала, человек шагает, человек бежит, группа людей шагают, группа людей бежат и транспортное средство). Полученный порядок параметров авторегрессивных моделей установлен с порядком, указанным с помощью информационного критерия, предложенного со стороны Акаике для различных типов окон. После уменьшения размеров полученных векторов признаков, выделенных с помощью реальных радиолокационных сигналов, показано, что предлагаемые меры предлагают значительно меньше авторегрессивных порядков и процессов с увеличением сепарируемости рассматриваемого класса радиолокационных целей.
\end{abstract}

Ключевые слова: разведывательная радиолокационная станция, радиолокационные сигналы, классификации сигналов, авторегрессивные модели.

\section{La sélection de l'ordre des paramètres des modèles autorégressifs pour la classification des cibles des radars de surveillance}

\begin{abstract}
Dans cette recherche on considère la sélection de l'ordre des paramètres chez les modèles autorégressifs pour la classification des signaux de la sortie chez les radars de surveillance. Dans ce but on a proposé la mesure basée sur la séparabilité maximale de classes étudiées des cibles de radar ( il n'y a pas de signal de radar, la personne marche, la personne court, un groupe de personnes en marche, un groupe de personnes court et le véhicule) . L'ordre obtenu des paramètres des modèles autorégressifs a été comparé avec l'ordre déterminé par les critères informatiques proposé par Akaike pour les différentes formes des fenêtres. Après la réduction des dimensions des vecteurs obtenus séparés par l'utilisation des signaux réels de radar on a démontré que la mesure proposée suggérait un ordre considérablement plus petit des processus autorégressifs avec la séparabilité augmentée chez les classes des cibles de radar considérées.
\end{abstract}

Mots clés: radar de surveillance, signaux de radar, classification des signaux, modèle autorégressif. 